\title{
Celebrity Suicides and Their Differential Influence on Suicides in the General Population: A National Population-Based Study in Korea
}

\author{
Woojae Myung ${ }^{1}$, Hong-Hee Won², Maurizio Fava ${ }^{3}$, David Mischoulon ${ }^{3}$, Albert Yeung ${ }^{3}$, \\ Dongsoo Lee ${ }^{1}$, Doh Kwan Kim¹, and Hong Jin Jeon ${ }^{1,3,4 凶}$ \\ ${ }^{1}$ Department of Psychiatry, Depression Center, Samsung Medical Center, Sungkyunkwan University School of Medicine, Seoul, Republic of Korea \\ ${ }^{2}$ Samsung Biomedical Research Institute, Samsung Medical Center, Sungkyunkwan University School of Medicine, Seoul, Republic of Korea \\ ${ }^{3}$ Depression Clinical and Research Program, Massachusetts General Hospital, Harvard Medical School, Boston, MA, USA \\ ${ }^{4}$ Department of Clinical Research Design and Evaluation and Department of Medical Device Management and Research, Samsung Advanced \\ Institute for Health Sciences \& Technology (SAIHST), Sungkyunkwan University, Seoul, Republic of Korea
}

Objective Although evidence suggests that there is an increase in suicide rates in the general population following celebrity suicide, the rates are heterogeneous across celebrities and countries. It is unclear which is the more vulnerable population according to the effect sizes of celebrity suicides to general population.

Methods All suicide victims in the general population verified by the Korea National Statistical Office and suicides of celebrity in South Korea were included for 7 years from 2005 to 2011. Effect sizes were estimated by comparing rates of suicide in the population one month before and after each celebrity suicide. The associations between suicide victims and celebrities were examined.

Results Among 94,845 suicide victims, 17,209 completed suicide within one month after 13 celebrity suicides. Multivariate logistic regression analyses revealed that suicide victims who died after celebrity suicide were significantly likely to be of age 20-39, female, and to die by hanging. These qualities were more strongly associated among those who followed celebrity suicide with intermediate and high effect sizes than lower. Younger suicide victims were significantly associated with higher effect size, female gender, white collar employment, unmarried status, higher education, death by hanging, and night-time death. Characteristics of celebrities were significantly associated with those of general population in hanging method and gender.

Conclusion Individuals who commit suicide after a celebrity suicide are likely to be younger, female, and prefer hanging as method of suicide, which are more strongly associated in higher effect sizes of celebrity suicide.

Psychiatry Investig 2015;12(2):204-211

Key Words Celebrity, Suicide, South Korea, Effect size.

\section{INTRODUCTION}

Suicide is a major cause of death worldwide and almost one million people die from suicide every year, representing a global mortality rate of 16 per 100,000. ' 'Copycat' suicides following the suicide of celebrities are important for understand-

Received: January 11, 2014 Revised: March 15, 2014

Accepted: May 14, 2014 Available online: March 18, 2015

$\triangle$ Correspondence: Hong Jin Jeon, MD, PhD

Department of Psychiatry, Depression Center, Samsung Medical Center, Sungkyunkwan University School of Medicine, 81 Irwon-ro, Gangnam-gu, Seoul 135710 , Republic of Korea

Tel: +82-2-3410-3586, Fax: +82-2-3410-0050, E-mail: jeonhj@skku.edu

(a) This is an Open Access article distributed under the terms of the Creative Commons Attribution Non-Commercial License (http://creativecommons.org/licenses/bync/3.0) which permits unrestricted non-commercial use, distribution, and reproduction in any medium, provided the original work is properly cited. ing the increase of national suicide rates. Previous studies have revealed that celebrity suicide increases the number of suicides $^{2-6}$ and suicide attempts ${ }^{7}$ in the general population, mediated by excessive media coverage $e^{3-5}$ and spread of information about the suicide methods of celebrities. ${ }^{8}$ Celebrity suicide influences the general population by a modeling effect, ${ }^{4}$ also called the Werther effect. ${ }^{9}$ Vulnerable individuals may regard suicide as an acceptable solution to personal problems, based on their interpretation of media broadcasts, and consequently adopt suicidal behavior. ${ }^{10}$

Having focused on the influence of a major celebrity suicide, only a few studies compared their influence from multiple celebrities. Although a meta-analysis of 419 cases from 55 studies revealed that celebrity suicides were 5.27 times more likely to produce a copycat effect than non-celebrity suicides, ${ }^{11}$ an 
increase in suicide rates after a celebrity suicide displays substantial heterogeneity between celebrities and countries. ${ }^{12}$ Furthermore, few studies have focused on the characteristics of suicide victims in the general population after multiple celebrity suicides and their associations with those of celebrities. It is still unclear whether there is a group more vulnerable to the influence of celebrity suicide.

Over the last decade, South Korea has shown a sharply increasing suicide rate in the general population. During this time, Korean celebrity suicides include Ms. Choi, a renowned television actress for 20 years, her brother, and a former president. The number of suicide deaths increased from 26.1/ 100,000 persons in 2005 to $31.7 / 100,000$ persons in $2011 .^{13}$ South Korea ranked as the third highest among 105 countries in the 2011 World Health Organization Suicide prevention (SUPRE) data. ${ }^{1}$ In particular, suicide is the leading cause of death in younger people (10-39 years) in South Korea, and women displayed a higher suicide rate than men compared with Western countries. ${ }^{14}$

We hypothesized that South Koreans who commit suicide after a celebrity suicide may demonstrate specific qualities concerning age, gender, and are likely to prefer methods of suicide in higher effect sizes to suicide of general population in Korea, compared with lower effect sizes. These specifics may reflect the age, gender, and method of suicide of the decreased celebrity.

\section{METHODS}

\section{Suicide data}

The number of completed suicides in South Korea from January 1, 2005 to December 31, 2011 was obtained from the database of the Korea National Statistical Office (KNSO, http:// kostat.go.kr/portal/english). This database provides demographic characteristics of suicide victims, time of death, and method chosen. The data were examined and verified by KNSO. Suicides were classified according to the International Classification of Diseases-10 (ICD-10) codes in the range of X60-X84, which include suicides from all causes including intentional self-poisoning and self-harm. ${ }^{15}$

The data from the preceding 5 years of suicide deaths were used for analysis to allow adjustment for seasonal variation. ${ }^{16,17}$ Monthly 5-year averages of suicide numbers from 2000 to 2004 were also included in analyses. In addition, meteorological data (sunlight hours and temperature) and economic data (Korea Composite Stock Price Index, consumer price index and unemployment rate) were obtained as previously described. ${ }^{17}$

\section{Celebrity suicide}

Based on previous studies of celebrity suicides, ${ }^{3,17-19}$ news media archives were used to identify the suicides of well-known persons. We included entertainers, professional athletes, politicians, writers, and chief executive officers. A systematic search was conducted for media reports of suicides in South

Table 1. Celebrity suicide* and suicide in the general population of Korea from 2005 to 2011 (N=94845)

\begin{tabular}{|c|c|c|c|c|c|c|c|c|}
\hline \multirow[t]{2}{*}{ Number } & \multirow[t]{2}{*}{ Year } & \multirow[t]{2}{*}{ Age } & \multirow[t]{2}{*}{ Sex } & \multirow[t]{2}{*}{ Occupation } & \multirow[t]{2}{*}{ Suicide method } & \multicolumn{3}{|c|}{$\begin{array}{l}\text { Number of suicide victims within one month } \\
\text { before and after celebrity suicide (person/day) }\end{array}$} \\
\hline & & & & & & Before (a) & After (b) & (b)-(a) \\
\hline 1 & 2005 & 24 & $\mathrm{~F}$ & Actress & Hanging & 22.93 & 41.10 & 18.17 \\
\hline 2 & 2007 & 25 & $\mathrm{~F}$ & Singer & Hanging & 21.17 & 32.85 & 11.68 \\
\hline 3 & 2007 & 26 & $\mathrm{~F}$ & Actress & Hanging & 21.17 & 44.50 & 23.33 \\
\hline 4 & 2008 & 40 & M & Baseball player & Jumping & 31.00 & 32.57 & 1.57 \\
\hline 5 & 2008 & 36 & M & Actor & Gas poisoning & 32.47 & 37.13 & 4.66 \\
\hline 6 & 2008 & 39 & $\mathrm{~F}$ & Actress & Hanging & 32.47 & 58.60 & 26.13 \\
\hline 7 & 2009 & 29 & $\mathrm{~F}$ & Actress & Hanging & 38.43 & 46.20 & 7.77 \\
\hline 8 & 2009 & 62 & M & Former president & Jumping & 50.37 & 53.53 & 3.17 \\
\hline 9 & 2010 & 39 & $\mathrm{M}$ & Actor & Hanging & 38.43 & 50.53 & 12.10 \\
\hline 10 & 2010 & 32 & $\mathrm{M}$ & Actor & Hanging & 45.97 & 52.80 & 6.83 \\
\hline 11 & 2010 & 63 & F & Writer & Hanging & 42.87 & 45.03 & 2.17 \\
\hline 12 & 2011 & 29 & $\mathrm{~F}$ & Announcer & Jumping & 49.30 & 57.27 & 7.97 \\
\hline 13 & 2011 & 72 & M & Businessman & Hanging & 43.73 & 39.90 & -3.83 \\
\hline Total & & & & & & 36.18 & 45.54 & 9.36 \\
\hline
\end{tabular}

*celebrity suicide was defined as a suicide which was broadcast by news programs of the three major national television networks for more than a week 
Korea from January 1, 2005 to December 31, 2011 using the web-based news archive of the Korea Press Foundation (Korean Integrated News Database System, KINDS; http://www. kinds.or.kr) that stores all news articles from national television networks and major newspapers. News articles were retrieved by a search using the keyword "suicide", and were checked to ascertain whether they were news stories about suicide victims. We defined a celebrity suicide as a suicide reported for more than a week in news programs of the three major Korean national television networks. Thirteen celebrity suicides were identified in the study period. Details of the cases of celebrity suicide are summarized in Table 1.

In addition, we defined the affected period as one month (30 days) after the first report of the celebrity suicide based on previous studies. ${ }^{1720}$ The reference periods were defined as one month (30 days) preceding the first report of the celebrity suicide. ${ }^{12}$ Overlapping intervals were included in the later celebrity suicide period, and shared the former reference period.

\section{Statistical analyses}

We employed the multivariate regression model to estimate the effect size of celebrity suicide incidents. Five-year averages of monthly national suicide rates, and economic and meteorological variables that have been considered classical suicide predictors were included as covariates in this regression model. Individual effect estimates were meta-analyzed with the DerSimonian-Laird random effect mode ${ }^{21}$ to obtain a combined effect size using METASOFT software..$^{22}$ According to the effect estimates, we divided celebrity suicide cases into three affected period groups: low ( $<10$ suicides), intermediate (10-20 suicides) and high ( $>20$ suicides). Logistic regression was employed to control covariates in the testing of the association between categorical variables. Pearson's chisquare test was used to test for association between characteristics of the celebrities and characteristics of suicide victims during the relevant periods. Linear regression was employed for comparison of age of suicide victims among the period groups. All statistical analyses were performed by using the $\mathrm{R}$ software or PASW18.0 for Microsoft Windows (SPSS Inc., Chicago, IL, USA).

\section{RESULTS}

\section{Effect size of a celebrity suicide}

Thirteen suicides met the definition of celebrity suicide during the 7 years of this study. The characteristics and the impact of these 13 cases are summarized in Table 1 . The incidents comprised seven females and six males, and among them eight persons were entertainers. During the periods of celebrity suicides, two overlapped intervals were found between

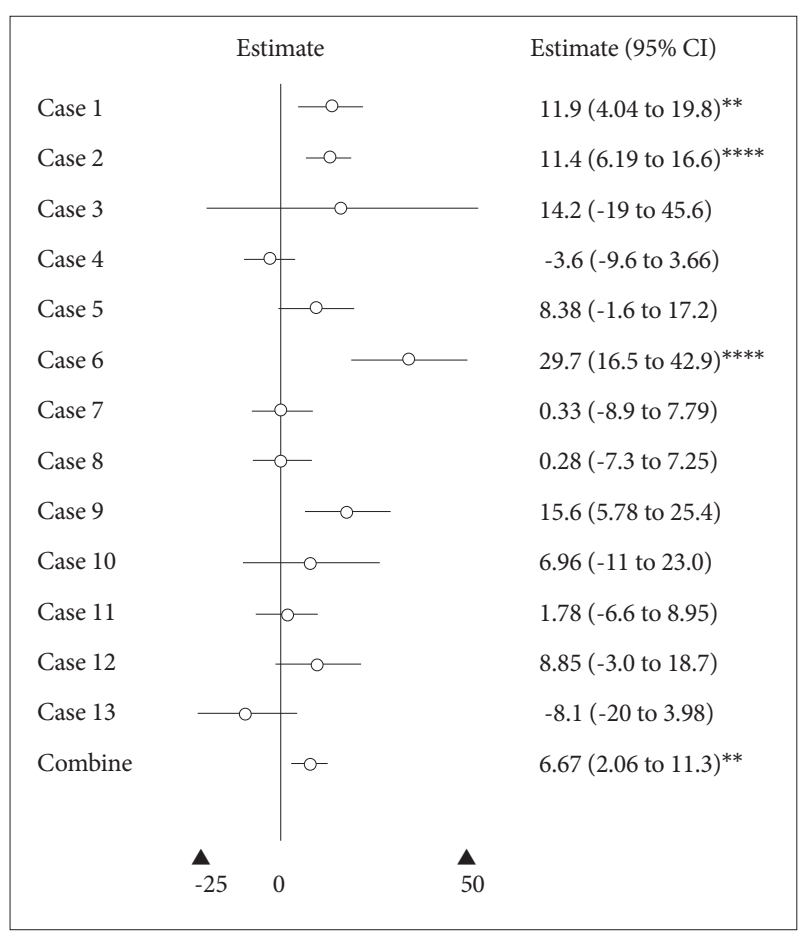

Figure 1. Forest plot of effect estimates in suicide numbers during affected periods compared with reference periods, and $95 \%$ confidence intervals ( $\mathrm{Cls}$ ) from 13 celebrity suicides. The pooled random-effects estimate and the corresponding $95 \% \mathrm{Cl}$ are also shown $(n=94845) .{ }^{* *} p<0.01,{ }^{* * * *} p<0.0001$.

case 2 and case 3 , and between case 5 and case 6 . Notably, the most common suicide method of these celebrities was hanging (69.2\%).

Figure 1 displays the Forest plot of estimates for changes in suicide numbers during affected periods compared with reference periods. Among 94,845 suicide victims, 17,209 completed suicide within one month after a celebrity suicide (18.1\%). Effect sizes after celebrity suicide showed a large variation, from -8.1 to 29.7. The random-effects combined estimate of 13 celebrity suicides indicated an average increase in the daily suicide number of 6.7 [95\% confidence interval (CI) 2.1-11.3] in the affected periods. Four relevant periods (for cases 1, 2, 6 and 9) showed a significant increasing effect. The suicide of a famous actress Ms. Choi (case 6), led to the biggest change of national daily suicide numbers (estimate $=29.7,95 \%$ CI $16.5^{-}$ 42.9).

\section{Difference between characteristics of public suicide victims on affected periods according to the effect sizes of celebrity suicides}

We conducted a multivariate logistic regression analysis of suicide victims within one month after celebrity suicide (coded 1), compared with those within one month before (coded 0 ) by entering all characteristics of suicide victims and monthly averages of suicide numbers of preceding five-year as indepen- 
Table 2. Multivariate logistic regression analysis of suicide victims within one month after celebrity suicide $(\mathrm{N}=17,209)$, compared with those one month before $(\mathrm{N}=12,500)$

\begin{tabular}{|c|c|c|c|}
\hline \multirow{2}{*}{ Variables } & \multicolumn{3}{|c|}{ Suicide victims within one month after celebrity suicide } \\
\hline & Person/Day & Adjusted OR (95\% CI) & $\mathrm{p}$ \\
\hline \multicolumn{4}{|l|}{ Gender } \\
\hline Male & 29.28 & 1 & \\
\hline Female & 16.74 & $1.15(1.09-1.21)$ & $<0.0001$ \\
\hline \multicolumn{4}{|l|}{ Age (years) } \\
\hline$\geq 60$ & 14.60 & 1 & \\
\hline $40-59$ & 16.16 & $1.01(0.94-1.08)$ & 0.81 \\
\hline $20-39$ & 14.02 & $1.12(1.03-1.23)$ & 0.01 \\
\hline$<20$ & 1.23 & $1.01(0.85-1.20)$ & 0.89 \\
\hline \multicolumn{4}{|l|}{ Occupation } \\
\hline White collar & 9.39 & 1 & \\
\hline Blue collar & 6.74 & $1.03(0.94-1.12)$ & 0.55 \\
\hline Unemployed, housewife or students & 28.12 & $0.98(0.92-1.04)$ & 0.49 \\
\hline \multicolumn{4}{|l|}{ Marital status } \\
\hline Married & 21.25 & 1 & \\
\hline Single & 13.06 & $1.03(0.95-1.11)$ & 0.50 \\
\hline Divorced & 5.88 & $1.03(0.95-1.11)$ & 0.46 \\
\hline Widowed & 5.56 & $0.90(0.83-0.98)$ & 0.02 \\
\hline \multicolumn{4}{|l|}{ Education level } \\
\hline College & 8.14 & 1 & \\
\hline High school or less & 32.97 & $1.05(0.98-1.12)$ & 0.15 \\
\hline Uneducated & 4.20 & $1.00(0.90-1.12)$ & 0.97 \\
\hline \multicolumn{4}{|l|}{ Suicide method } \\
\hline Hanging & 25.99 & $1.26(1.18-1.34)$ & $<0.0001$ \\
\hline Poisoning & 11.26 & $0.99(0.92-1.07)$ & 0.86 \\
\hline Jumping or others & 8.67 & 1 & \\
\hline \multicolumn{4}{|l|}{ Suicide time } \\
\hline Dawn (0-6 AM) & 8.49 & 1 & \\
\hline Morning (7-12 AM) & 12.52 & $0.93(0.87-1.00)$ & 0.05 \\
\hline Afternoon (1-6 PM) & 13.15 & $0.91(0.85-0.98)$ & 0.01 \\
\hline Evening (7-12 PM) & 11.84 & $1.01(0.93-1.08)$ & 0.90 \\
\hline
\end{tabular}

OR: odds ratio, $\mathrm{CI}$ : confidence interval

dent variables (Table 2)

Suicide victims who died after celebrity suicide were significantly likely to be female ( $\mathrm{p}<0.0001), 20-39$ years of age $(\mathrm{p}=$ $0.011)$, widowed $(\mathrm{p}=0.017)$, to die by hanging $(\mathrm{p}<0.0001)$ and to die in the afternoon $(\mathrm{p}=0.011)$.

Next, we tested the differences of characteristics of suicide victims between intermediate or high effect size groups (coded 1) and the low effect size group (coded 0 ) by employing multivariate logistic regression analysis (Table 3 ). These qualities were more strongly associated among those who showed intermediate and high effect sizes than lower. Death by hanging $(\mathrm{p}<0.0001)$ and gender $(\mathrm{p}<0.0001)$ were significantly associated with those of the general population. Single marital status was negatively associated with intermediate or high effect size group, and high school or lower education level was significantly associated with intermediate or high effect size group. When the four different age groups were considered, there were increases among three groups $<59$ years of age compared with those $\geq 60$ years of age. This was reconfirmed in linear regression analysis-as the effect size of the celebrity suicide increased, the average age of public suicide victims decreased $(\mathrm{p}<$ 0.0001) (Table 4). 
Table 3. Multivariate logistic regression analysis of suicide victims within one month after celebrity suicide with intermediate or high effect size $(N=6,499)$, compared with suicide victims within one month after celebrity suicide with low effect size $(N=10,710)$

\begin{tabular}{|c|c|c|c|}
\hline \multirow{2}{*}{ Variables } & \multicolumn{3}{|c|}{ Suicide victims within one month after celebrity suicide with intermediate or high effect size } \\
\hline & Person/Day & Adjusted OR (95\% CI) & $\mathrm{p}$ \\
\hline \multicolumn{4}{|l|}{ Gender } \\
\hline Male & 37.54 & 1 & \\
\hline Female & 24.95 & $1.22(1.13-1.31)$ & $<0.0001$ \\
\hline \multicolumn{4}{|l|}{ Age (years) } \\
\hline$\geq 60$ & 17.44 & 1 & \\
\hline $40-59$ & 21.81 & $1.24(1.13-1.36)$ & $<0.0001$ \\
\hline $20-39$ & 21.58 & $1.55(1.38-1.75)$ & $<0.0001$ \\
\hline$<20$ & 1.66 & $1.36(1.09-1.72)$ & 0.01 \\
\hline \multicolumn{4}{|l|}{ Occupation } \\
\hline White collar & 13.24 & 1 & \\
\hline Blue collar & 8.88 & $1.10(0.98-1.23)$ & 0.10 \\
\hline Unemployed, housewife or students & 38.19 & $1.03(0.94-1.12)$ & 0.57 \\
\hline \multicolumn{4}{|l|}{ Marital status } \\
\hline Married & 28.37 & 1 & \\
\hline Single & 18.75 & $0.90(0.81-0.99)$ & 0.03 \\
\hline Divorced & 7.71 & $0.91(0.82-1.01)$ & 0.09 \\
\hline Widowed & 7.05 & $1.01(0.90-1.14)$ & 0.87 \\
\hline \multicolumn{4}{|l|}{ Education level } \\
\hline College & 11.12 & 1 & \\
\hline High school or less & 45.28 & $1.10(1.01-1.20)$ & 0.04 \\
\hline Uneducated & 5.19 & $1.07(0.92-1.24)$ & 0.40 \\
\hline \multicolumn{4}{|l|}{ Suicide method } \\
\hline Hanging & 38.71 & $1.40(1.29-1.53)$ & $<0.0001$ \\
\hline Poisoning & 13.33 & $1.05(0.94-1.16)$ & 0.38 \\
\hline Jumping and others & 10.45 & 1 & \\
\hline \multicolumn{4}{|l|}{ Suicide time } \\
\hline Dawn (0-6 AM) & 11.22 & 1 & \\
\hline Morning (7-12 AM) & 17.13 & $1.08(0.98-1.19)$ & 0.13 \\
\hline Afternoon (1-6 PM) & 17.83 & $1.06(0.97-1.17)$ & 0.21 \\
\hline Evening (7-12 PM) & 16.32 & $1.08(0.98-1.19)$ & 0.11 \\
\hline
\end{tabular}

OR: odds ratio, CI: confidence interval

\section{Association between characteristics of the celebrities and characteristics of public suicide victims on the affected periods}

The proportion of female suicide victims during the relevant periods of female celebrity suicide was significantly larger than that seen during male celebrity suicide periods $(38.5 \%$ vs. $33.8 \%, \mathrm{p}<0.0001$ ) (Table 5). Significance was preserved after controlling for characteristics of suicide victims and celebrities, and monthly averages of suicide numbers in the preceding 5 years of celebrity's suicide death $(p<0.0001)$.

The method of suicide chosen by celebrities was associated with the suicide method of victims during the affected periods. The proportion of hanging suicide on the relevant periods for celebrities who died by other methods was similar to the proportion during unaffected periods which means the period within one month before celebrity suicide $(50.8 \%$ vs. $49.0 \%)$. However, it increased to $59.6 \%$ during the periods of hanging-related suicide of celebrities. There was a significant association between the method of suicide chosen by a celebrity and the method chosen by suicide victims in the general population during the relevant periods $(\mathrm{p}<0.0001)$ (Table 5). Moreover, this association was robust in logistic regression 
W Myung et al.

Table 4. Linear regression analysis for the association between age of suicide victims and the variables in the general population ( $\mathrm{N}=94845)$

\begin{tabular}{|c|c|c|c|c|}
\hline \multirow{2}{*}{ Variables } & \multicolumn{4}{|c|}{ Association with age of suicide victims } \\
\hline & Beta $(95 \% \mathrm{CI})$ & SE & $\mathrm{t}$ & $\mathrm{p}$ \\
\hline Effect size* & $-0.67(-0.81$ to -0.53$)$ & 0.07 & -9.29 & $<0.0001$ \\
\hline Gender (female) & $-2.21(-2.39$ to -2.02$)$ & 0.09 & -23.43 & $<0.0001$ \\
\hline Occupation (white collar) & $-8.13(-8.36$ to -7.90$)$ & 0.12 & -69.59 & $<0.0001$ \\
\hline Marital status (single) & $-24.83(-25.03$ to -24.63$)$ & 0.10 & -240.17 & $<0.0001$ \\
\hline Education (high school or higher) & $-5.91(-6.15$ to -5.66$)$ & 0.12 & -47.56 & $<0.0001$ \\
\hline Suicide method (hanging) & $-2.67(-2.84$ to -2.49$)$ & 0.09 & -29.73 & $<0.0001$ \\
\hline Suicide time (night) & $-1.11(-1.32$ to -0.91$)$ & 0.10 & -10.85 & $<0.0001$ \\
\hline 5-year averages of suicide numbers & 0.003 (0.003 to 0.004$)$ & $<0.001$ & 13.11 & $<0.0001$ \\
\hline Constant & $-59.60(59.07$ to 60.12$)$ & 0.27 & 223.10 & $<0.0001$ \\
\hline
\end{tabular}

*effect size was entered as a continuous variable; the suicides which occurred within unaffected periods were coded 0 and suicide which occurred within affected period were coded 1,2, and 3 for low, intermediate and high group, respectively. CI: confidence interval, SE: standard error

Table 5. Association between characteristics of the celebrities and characteristics of suicide victims within one month after celebrity suicide $(\mathrm{N}=17,209)$

\begin{tabular}{|c|c|c|c|c|}
\hline \multirow{3}{*}{ Celebrity } & \multirow{2}{*}{\multicolumn{2}{|c|}{ Number of suicide victims* }} & \multicolumn{2}{|c|}{ Logistic regression analysis $^{\dagger}$} \\
\hline & & & \multirow[t]{2}{*}{ Adjusted OR (95\% CI) } & \multirow[t]{2}{*}{$\mathrm{p}$} \\
\hline & Female & Male & & \\
\hline Female & $3636(38.5 \%)$ & $5802(61.5 \%)$ & $1.19(1.10-1.29)$ & $<0.0001$ \\
\hline \multirow[t]{2}{*}{ Male } & $2624(33.8 \%)$ & $5147(66.2 \%)$ & & \\
\hline & $\geq 60$ years & Others & & \\
\hline$\geq 60$ years & $1438(34.6 \%)$ & $2716(65.4 \%)$ & $0.90(0.77-1.06)$ & 0.20 \\
\hline \multirow[t]{2}{*}{ Others } & $4021(30.8 \%)$ & $9034(69.2 \%)$ & & \\
\hline & Hanging & Others & & \\
\hline Hanging & $7166(59.6 \%)$ & $4851(40.4 \%)$ & $1.35(1.22-1.50)$ & $<0.0001$ \\
\hline Others & $2556(50.8 \%)$ & $2636(49.2 \%)$ & & \\
\hline
\end{tabular}

*within one month after celebrity suicide, +logistic regression analysis adjusted for characteristics of suicide victim, characteristics of celebrities and previous five-year averages of suicide numbers. OR: odds ratio, CI: confidence interval

$(\mathrm{p}<0.0001)$. This association could be found between the periods of falling-related celebrity suicide and number of suicide victims by falling on the affected periods $(\mathrm{p}<0.0001)(\mathrm{Ta}-$ ble 5). However, there was no significant effect of age of celebrity on the age of suicide victims in the affected periods after controlling for other variables.

\section{DISCUSSION}

This is the first study to examine the characteristics of suicide victims among the general population after celebrity suicides in a national sample according to their effect sizes to suicide of general population. This study presents two main findings. First, individuals who commit suicide after a celebrity suicide are likely to be 20-30 years of age, female, and prefer hanging as the method of suicide, which are more strongly associated with celebrity suicide in intermediate or high effect sizes, compared with lower effect size. Second, characteristics of suicide victims are associated with those of celebrities.

This study revealed heterogeneity on the effect sizes of celebrity suicides from -8.1 to 29.7 for the last 7 years in South Korea. The suicide of the famous television actress Ms. Choi produced the highest effect size during that time, followed by the suicide of her younger brother who was an actor and singer. Among 13 celebrity suicides, actors, actresses, and singers produced higher effect sizes than other celebrities, such as a baseball player, former president, writer, announcer, and company executive. However, there is a possibility that the overlapped intervals between case 2 and case 3 , and between case 5 and case 6 could be influence on effect sizes of celebrity of actresses. The effect of later celebrity suicide could be exaggerated by former celebrity suicide.

The higher effect size of celebrity suicides was associated with a younger age of suicide victims and with female gender based on linear regression analysis. Celebrity suicide with intermediate or high effect sizes showed a stronger association 
with those who were 20-30 years old, female, and preferred hanging as the method of suicide, rather than the lower effect size of celebrity suicide. This suggests that young women are more vulnerable to suicide and they choose hanging as method of suicide when celebrity suicide has a strong influence on the general population. A speculation is that the younger women are more susceptible to media influence regarding celebrity suicides as proposed in previous studies. ${ }^{4,23}$ In addition, our results suggest this connection was stronger for actors, actresses, and signers than for other celebrities.

Females and younger people are more vulnerable to suicide after celebrity suicide than men and older age groups. ${ }^{23,24}$ Presently, the age of individuals who committed suicide after a celebrity suicide was younger than the age of celebrities, with a mean age of 39.7 years, and age was not significantly associated with those of celebrities after controlling for covariates. A previous study also reported that suicide victims after celebrity suicide are younger than the celebrities. ${ }^{3}$

This study also showed hanging was the most common method after celebrity suicide, which was associated with the suicide method of celebrities. Previous studies showed that suicide methods were different and closely associated with those of celebrities. A study from Taiwan reported charcoal burning was the most common method of suicide after the similar suicide of a young female singer. ${ }^{23}$ Another study from Taiwan reported hanging was the most common after the suicide of a television actor by hanging. ${ }^{4}$ A study from Germany reported that railway suicide increased after the railway suicide of a famous football player. ${ }^{25}$ By showing the same specific method increases after celebrity suicide, Fu et al. ${ }^{3}$ suggested that as people identify more with the celebrity, their risk for suicide rises. Restricting access to lethal means is an effective way to prevent suicide. ${ }^{26}$ Although ropes and other accessories used in hanging are more difficult to restrict than other methods, such as pesticides or gas poisoning, prevention strategies include installing break-away closet bars and shower taps, lowering the height of anchor points and increasing the awareness of risk indicators. ${ }^{27}$

In our results, suicide victims who followed celebrity suicide were significantly likely to die in the afternoon. However, there could be marked difference between time of suicide attempt and time of death. To be informative to prevent copycat suicide, further research with more precise data would be required.

Although this study was based on a larger number of suicide victims and more celebrities than previous studies, it is impossible to figure out whether individuals who committed suicide within one month after celebrity suicide were directly influenced by the suicide of celebrities or not. A previous study with face-to-face interviews for suicide attempters re- vealed that suicide of a celebrity was followed by an increase in suicide attempts of general population because of extensive media reporting. ${ }^{28}$ This study showed an increase of suicide victims of from 36.2-45.5 persons/day after the suicides of 13 celebrities. Misclassification and under-reporting of suicides in the registry system might have confounded the findings of this study.

Impact of media reporting about celebrity suicides on suicide rates within short period has been widely reported. ${ }^{2-4,7,12}$ In this study, we confirmed this effect by the definition of celebrity based on news media archives. Our results could be an additional evidence of the necessity of guidelines on media reporting of suicide for the prevention. ${ }^{12}$

In conclusion, individuals who commit suicide after a celebrity suicide are likely to be younger, female, and prefer hanging as method of suicide, which are more strongly associated in higher effect sizes of celebrity suicide. This study suggests that a suicide prevention system should be essential for young individuals and for women when a celebrity who has a great potential effect size dies from suicide. Celebrities who are young and female may have a greater impact on suicide of the general population than older individuals and men. Thus, suicide prevention for celebrities is needed, especially focusing on young women and prevention of the same method of suicide with that of celebrities. Approaches to suicide prevention are needed to target high-risk groups, and particularly strategies based on psychiatric disorders, notably mood, substance-related, anxiety, psychotic, and personality disorders, ${ }^{29}$ these strategies should also focus on celebrities who have potential influence on general population particularly actors, actresses, and singers. Provision of mental health service and increase of its accessibility may help to prevent suicide and suicidal behaviors for vulnerable populations, and celebrities themselves. ${ }^{30}$

\section{Acknowledgments}

This research was supported by the Basic Science Research Program through the National Research Foundation of Korea (NRF) funded by the Ministry of Education, Science and Technology (No. 2011-0013064). This research was also supported by the Samsung Medical Center Clinical Research Development Program (CRDP) Grant SMO1131461. We appreciate the Korea National Statistical Office (KNSO) and the Korea Press Foundation for their support and cooperation.

\section{REFERENCES}

1. WHO Worldwide Initiative for the Prevention of Suicide. WHO Suicide Prevention. Geneva: World Health Organization; 2011.

2. Fu KW, Chan $\mathrm{CH}$. A study of the impact of thirteen celebrity suicides on subsequent suicide rates in South Korea from 2005 to 2009. PLoS One 2013;8:e53870.

3. Fu KW, Yip PS. Estimating the risk for suicide following the suicide deaths of 3 Asian entertainment celebrities: a meta-analytic approach. J Clin Psychiatry 2009;70:869-878. 
4. Cheng AT, Hawton K, Lee CT, Chen TH. The influence of media reporting of the suicide of a celebrity on suicide rates: a population-based study. Int J Epidemiol 2007;36:1229-1234.

5. Yip PS, Fu KW, Yang KC, Ip BY, Chan CL, Chen EY, et al. The effects of a celebrity suicide on suicide rates in Hong Kong. J Affect Disord 2006; 93:245-252.

6. Kunrath S, Baumert J, Ladwig KH. Increasing railway suicide acts after media coverage of a fatal railway accident? An ecological study of 747 suicidal acts. J Epidemiol Community Health 2011;65:825-828.

7. Jeong J, Shin SD, Kim H, Hong YC, Hwang SS, Lee EJ. The effects of celebrity suicide on copycat suicide attempt: a multi-center observational study. Soc Psychiatry Psychiatr Epidemiol 2012;47:957-965.

8. Yip PS, Caine E, Yousuf S, Chang SS, Wu KC, Chen YY. Means restriction for suicide prevention. Lancet 2012;379:2393-2399.

9. Phillips DP. The influence of suggestion on suicide: substantive and theroretical implications of the Werther effect. Am Sociol Rev 1974;39: 340-354.

10. Blood RW, Pirkis J. Suicide and the media. Part III: theoretical issues. Crisis 2001;22:163-169.

11. Stack S. Suicide in the media: a quantitative review of studies based on non-fictional stories. Suicide Life Threat Behav 2005;35:121-133.

12. Niederkrotenthaler T, Fu KW, Yip PS, Fong DY, Stack S, Cheng Q, et al. Changes in suicide rates following media reports on celebrity suicide: a meta-analysis. J Epidemiol Community Health 2012;66:1037-1042.

13. Statistics Korea. 2011 Death and Cause of Death in Korea. Daejeon: Korea National Statistical Office; 2012.

14. WHO. Suicide Prevention (SUPRE) - the WHO Worldwide Initiative for the Prevention of Suicide. Geneva: World Health Organization; 2009.

15. Kim Y, Kim H, Kim DS. Association between daily environmental temperature and suicide mortality in Korea (2001-2005). Psychiatry Res 2011;186:390-396.

16. Eastwood M, Peacocke J. Seasonal patterns of suicide, depression and electroconvulsive therapy. Br J Psychiatry 1976;129:472-475.

17. Won HH, Myung W, Song GY, Lee WH, Kim JW, Carroll BJ, et al. Predicting national suicide numbers with social media data. PLoS one 2013;8:e61809.
18. Fu KW, Chan $\mathrm{CH}$. A study of the impact of thirteen celebrity suicides on subsequent suicide rates in South Korea from 2005 to 2009. PLoS one 2013;8:e53870.

19. Jonas K. Modelling and suicide: a test of the Werther effect. Br J Soc Psychol 1992;31:295-306.

20. Phillips DP. The influence of suggestion on suicide: substantive and theoretical implications of the Werther effect. Am Sociol Rev 1974: 340-354.

21. DerSimonian R, Laird N. Meta-analysis in clinical trials. Control Clin Trials 1986;7:177-188.

22. Han B, Eskin E. Random-effects model aimed at discovering associations in meta-analysis of genome-wide association studies. Am J Hum Genet 2011;88:586-598.

23. Chen YY, Liao SF, Teng PR, Tsai CW, Fan HF, Lee WC, et al. The impact of media reporting of the suicide of a singer on suicide rates in Taiwan. Soc Psychiatry Psychiatr Epidemiol 2012;47:215-221.

24. Hawton K, Harriss L, Simkin S, Juszczak E, Appleby L, McDonnell R, et al. Effect of death of Diana, princess of Wales on suicide and deliberate self-harm. Br J Psychiatry 2000;177:463-466.

25. Hegerl U, Koburger N, Rummel-Kluge C, Gravert C, Walden M, Mergl R. One followed by many?-Long-term effects of a celebrity suicide on the number of suicidal acts on the German railway net. J Affect Disord 2013;146:39-44.

26. Mann JJ, Apter A, Bertolote J, Beautrais A, Currier D, Haas A, et al. Suicide prevention strategies: a systematic review. JAMA 2005;294: 2064-2074.

27. Baker SP, Hu G, Wilcox HC, Baker TD. Increase in suicide by hanging/ suffocation in the U.S., 2000-2010. Am J Prev Med 2013;44:146-149.

28. Cheng AT, Hawton K, Chen TH, Yen AM, Chen CY, Chen LC, et al. The influence of media coverage of a celebrity suicide on subsequent suicide attempts. J Clin Psychiatry 2007;68:862-866.

29. Hawton K, van Heeringen K. Suicide. Lancet 2009;373:1372-1381.

30. While D, Bickley H, Roscoe A, Windfuhr K, Rahman S, Shaw J, et al. Implementation of mental health service recommendations in England and Wales and suicide rates, 1997-2006: a cross-sectional and beforeand-after observational study. Lancet 2012;379:1005-1012. 